\title{
Acting up or Acting out? Performing the Self in the Sex Work
}

\section{Arena}

\author{
Jan Marie \\ University of Western Sydney, Sydney, Australia
}

\begin{abstract}
Despite evidence to the contrary, policy makers, some researchers and many who provide health and social services to sex workers continue to reflect and reinforce the notion that sex workers are deviant and dysfunctional. This paper presents a portion of the results of a study which explicitly examined how indoor sex workers in Aotearoa/New Zealand look after their psychological wellbeing. Twelve women, who had worked as sex workers for at least three years, took part in semi-structured interviews and discussed how they looked after themselves both at work and in their wider social context. Interviews were transcribed and analysed using IPA (interpretative phenomenological analysis). This paper addresses gaps in the literature by exploring paths into sex work, positive aspects of the job and the use of the sex work arena to act out desire. Some sex workers developed an interest in sex work prior to their teen years in much the same way as another individual may develop an interest in any other occupation. Most chose sex work, because it fitted with their traits and skills. Most participants experienced a sense of satisfaction and enjoyment from the work. The narratives indicate that the sex worker role is considered to be an exaggeration or variation of usual heterosexual interactions. Having a work persona both create boundaries and allow for safe expression of the erotic self that is not possible in the usual social worlds of these women. The major conclusions drawn from the study are that prior understandings of sex work, personal traits and reasons for entering the sex industry are closely related to construction of a positive occupational identity and psychological wellbeing. It is important to note that sex work is legal in Aotearoa/New Zealand, thus, these findings reflect an experience of sex work that is conducted in an environment where the workers do not fear legal sanction.
\end{abstract}

Keywords: prostitution, women, sex work, feminism, psychology, wellbeing, New Zealand

\section{Introduction}

There is nothing simple about sex work or being a sex worker, it is a complicated business, full of contradictions and paradoxes. To adequately present, contextualizing and theorizing the lived sex worker experience is a difficult task. In light of this, the author decided to give primacy to the voices of these women and give less space to theorising. The reader was invited to engage with the narratives, to make links between what is already known and the stories here, and read iteratively, backwards and forwards to make connections among the pieces of narrative, the portraits of the women concerned and the wider context of sex work in Aotearoa/NewZealand.

It is estimated there were between 4,500 and 8,000 sex workers in Aotearoa/New Zealand (Jordan, 2005). Sex work is a legal activity in Aotearoa/New Zealand. The PRA (Prostitution Reform Act) was passed into law

Jan Marie, Ph.D. candidate, School of Psychology, University of Western Sydney. 
in 2003. The principal aims of this act are to protect sex workers from exploitation, protect children from commercial sexual exploitation, safeguard the human rights of sex workers and create an environment that is conducive to public health (PLRC (Prostitution Law Review Committee), 2008). In many respects, the law change has been successful. For this study, sex work was defined as sexual activity carried out in exchange for money, goods or services in lieu of money. The sexual activities include, but are not limited to penis vaginal intercourse, hand relief (masturbation), oral sex, sensual massage and fetish activities.

\section{Methodology}

This study was informed by FST (feminist standpoint theory) and conducted using the epistemology and methodology of IPA (Interpretive Phenomenological Analysis). Both IPA and FST aim to explore areas of concern rather than test a hypothesis generated by the researcher, and they both aim to add to the body of knowledge by contributing specific, context dependent, analytic accounts of participants' lived experience. Hein and Austin (2001) described this as providing "us with a deeper and fuller understanding of human existence, ourselves and others" (p. 4). Harding used the term "filling in the gaps" (1991). This paper fills some gaps by explicitly addressing aspects of the sex workers' experience that have been given scant attention in the literature.

\section{Procedure}

The beginning of the research process involved many lengthy preliminary discussions by e-mail, face-to-face, and over the telephone with people at venues ranging from sauna parlours, NZPC (New Zealand Prostitutes' Collective) offices, to social events and sex workers' own homes. Sex workers and the people who supported them wanted research to be useful, respectful, involve on-going consultation with sex workers and provide balance to what was already available in the literature. After much discussion, the author submitted the research proposal to NZPC early in 2007 and it received full support by this organisation. An ethics application was submitted to and reviewed by the Massey University Human Ethics Committee and approved in October 2007.

\section{Participants}

Participants were recruited by the snowballing method. To participate, women had to be over 25 years of age, so that they were outside of most definitions of "youth" and had enough maturity to be able to articulate their thoughts and processes around their self-care. They also had to have been involved in the sex industry for three years or more, a time length that would hopefully mean the women would have settled into routine aspects of the work and developed their own style of working and self-care strategies.

Twelve women agreed to take part in the study. They were all sex workers or ex-sex workers who believed that their sex work was not psychologically damaging to themselves and were willing to share their coping skills. Their ages ranged from 26 to 60 years (mean 39.75) and the length of time they had been working as a sex worker ranged from three to 25 years (mean 11.17).

\section{The Interviews}

Prior to each interview, the author spent considerable time with the participants explaining the purpose of the research, the topics the author wished to address, issues of confidentiality and how the data might be 
utilised. Semi-structured interviews were conducted with each of the 12 participants at a venue of their choice.

\section{Analysis}

As recommended by Smith, Jarman, and Osborn (1999), transcripts were read and themes identified. Two superordinate themes emerged from the data. The first, "Doing sex work”, relates to workplace practices. The second, "Being a sex worker", relates to how the women understood their experience of being a sex worker in their social contexts and how they cared for themselves in this arena. Themes drawn on here, are "Beginnings", from within the superordinate theme of "Being a sex worker", "Acting up or acting out?" and "It's a very special job" both from the superordinate theme of "Doing sex work".

\section{Introducing the Participants}

Participants in research were more than just "data mines". They had full lives outside of the area of investigation that is often ignored by researchers and by people who rely on myths and stereotypes to inform their understandings of deviant populations. For sex workers, this is particularly salient because of the strength of stereotypes and the interplay among "doing sex work" and "being a sex worker and wellbeing”. To present decontextualized snippets of lived experience to illustrate theoretical concepts and reinforce or contradict particular political notions could be considered dishonourable and is one reason why many sex workers were reluctant to take part in research. To counter this somewhat, the author presented miniature portraits of these women to provide some meaningful context to the narratives here and honor them as more than "just" sex workers. The following descriptions of the participants are as accurate as possible. Identifying details have been omitted or changed slightly to provide anonymity, and thus safety, for the participants.

Alice was 60. She started work at the age of 34 and had worked for 23 years. Alice worked in parlours in a large city. Alice understood sex work as enjoyable sex for money and described her work as mostly involving sexual encounters that she enjoyed rather than any sort of social service or onerous task. She stopped work because she was nearing retirement age and management practices at the parlour had changed. Alice had always been open about her sex work, and for many years, had worked in a social service that was supportive of sex workers and people with alternative sexualities. She had two adult children who knew about her work. The author interviewed Alice at NZPC Wellington office.

Casey was 33. She started work at the age of 18. Casey has worked in parlours, as a stripper and a dominatrix in the main centres. She aspired to become a sex therapist and began sex work as a career move to enhance her practical understanding of sex and sexuality. She loved being a sex worker. At the time of the interview, she was doing therapeutic and sensual massage from home. Casey had a business degree and published a successful alternative sexuality magazine. Separated, she shared the care of her two under five-year olds with their father. The author interviewed Casey at her home.

Chloe, who had a teenage daughter, is 38 and began sex work at the age of 23. She had moved in and out of the sex industry a number of times and currently runs a small owner operated brothel in a large city. She had expertise and experience in a variety of business and quasi-legal professions. Chloe is an opiate addict. Interestingly, during her times working in the sex industry she had always been "clean” or stable on low doses of methadone. She had a progressive neurological disorder and her employment options were becoming increasingly limited because of this. Chloe provides foster care for young people, many of whom do not receive state financial support. During the 12 months prior to the interview, she had provided shelter and care for ten 
young people. The author interviewed Chloe in her workplace.

Elizabeth was 51. At the age of 21, she worked in the streets of a large city for a few months. Later, at age 29, she left her career in the public sector and began work in a parlour. Elizabeth initially thought that sex work was like a nice social time and classified the client encounters as being about pleasure. Elizabeth was arrested, but not convicted for soliciting, which made her an unwelcome employee in the sex industry. She stopped work to concentrate on a career in a social service that is supportive of sex workers and people with alternative sexualities. The author interviewed Elizabeth at the beach.

Kathy started sex work at the age of 26, she is now 29. She had worked only in a parlour in a small city. Kathy loved being a sex worker. Kathy had three school age children who live by amicable arrangement in another town with their father. Kathy spent several months at a time living near her children, and ran a retail business while she is there. She lived with her partner, while away from their hometown, they engage in home maintenance work together. The author interviewed Kathy at a motel.

Laura was 41 . A trained chef, she started sex work around the age of 19 and continued to work as a chef. She worked as an escort and stripper in a parlour in a small city. Laura only ever worked for money, she used amphetamines and other drugs to cope with the work which she described as boring. Laura left sex work when her substance use became dangerous. When her first child was young, she returned to the industry briefly but decided it was not for her. Laura now owns a business in the hospitality sector. The author interviewed Laura at a motel.

Mary was 47. She initially entered the sex industry at the age of 37. She has moved in and out of the industry a number of times. Mary held a negative view of sex work and continually struggled with the moral dilemmas of doing sex work; she is clearly uncomfortable with being that "kind of woman". Having worked in parlours, Mary now works in a small owner operated brothel. She has two adult children. Her daughter, her daughter's partner and their three preschool children live with Mary. Working in the sex industry provides her with an income that allows her the time to focus on her grandchildren who delight her. The author interviewed Mary at her workplace.

Nina, who was 28 , entered the sex industry at the age of 18 , she worked for a year, then returned again at age of 22. All of her sex work has been in parlours; she was currently working in a small town. Nina always understood work as an acceptable way to earn money and was pragmatic about sex work, she enjoyed it and had no intention of leaving in the short term. For her, it was a pleasant way to earn income that suits her better than other options. Nina was a qualified chef and has a school aged child. She was active in the school community and coaches sports teams. The author interviewed her at her home.

Sally was 38. She started sex work at the age of 15 . Sally had worked intermittently in many venues around Aotearoa/New Zealand. At the time of the interview, she was working in a parlour in a small city. She has one preschool child. Sally is in the process of leaving the industry. She liked sex work and her decision to leave is solely to protect her son from stigma attached to being a sex worker. The author interviewed Sally at a motel.

Sue was 28 and started work at the age of 21. She had worked in parlours in a small city and ran her own parlour/escort agency for a few months. She had one child age five months. Sue had a neurological disorder and her employment options were limited. She began sex work to pay for cannabis, which she found that she reduced her symptoms. However, she hated the work and could only work when she was stoned on cannabis. Sue had experienced work-based government funded training schemes, but found these abusive and 
exploitative. She left the industry soon after our interview and was working as a cook. The author interviewed Sue at her home.

Vicky was 60 and worked privately as an escort and dominatrix for five years after entering the industry aged 53. Sex work was a part of her personal journey of exploring and enhancing her own sexuality. Interestingly, Vicky has been and continues to be a client. Vicky's main career was as a health professional. She ceased sex work because her health was failing. She has two adult children who do not know about her sex work. The author interviewed Vicky at her home.

Zoe was 27. She did one sex work job out of curiosity at about 13 or 14 . She re-entered the formal sex industry at the age of 18 , in between times she lived in a boarding house and was associated with an older man who sold her drugs and procured clients for her. Zoe explained her early independence as probably due to having attention deficit disorder and described her family life as not abusive in any way. She has four children who live with her. At the time of the interviews, Zoe was working in a brothel in a small city. The author interviewed Zoe in a motel.

\section{Results}

\section{Beginnings}

The theme "Beginnings" was in the superordinate theme of "Being", because ideas about sex work were developed in the wider social world. For most of the participants, these ideas were developed many years before entering the sex industry. Prior beliefs about sex work and sex workers were influenced by friends, family, media and life experiences. The participants did not enter the sex industry without considerable prior thought. Although immediate reasons for entering the industry have been explored in the literature, there were few discussions about why some women considered this to be a viable option. Sex workers came from a variety of backgrounds, ranging from extremes of poverty (Phoenix, 2000) to positions of privilege and well paid employment (Perkins \& Lovejoy, 2007). Reasons for entering the industry and beliefs about what it means to be a sex worker, are equally diverse. A full understanding of these reasons is important, because reasons for entering any industry and previous related experience are related to how the work is performed and how occupational identity is constructed (Ashforth \& Kreiner, 1999; Plumridge, 2005).

In the common understandings of prostitution and some of the literature, it is argued that people enter prostitution to support an addiction, were forced by pimps or boyfriends or because there were no other employment options available (Farley, 2004). However, many sex workers chose their occupations for the same reasons that other people do (Brewis \& Linstead, 2000; Jackson, Bennett, \& Sowinski, 2007). Although money was often the main reason discussed, there was nothing remarkable in this; it is the reason why most people engaged in paid work. It has been found that people who chose this work instead of equally well-paid employment thrived in the industry (Bernstein, 2007). Respondents might talk about money, because that is a socially acceptable explanation (Chapkis, 1997). Perhaps researchers seldom allow for alternative or positive explanations for becoming a sex worker, because it may be difficult to imagine why a person would do this job if it were not only for the money.

Many writings by sex workers provide a variety of explanations for entering the sex industry. They include a desire to work in an area that challenges normative heterosexuality (Leigh, 1997), as an extension of work that involves caring for people (Stubbs, 1994), an extension of academic research into the sex industry (Mistress, 2002) and a sexual or erotic practice that is related to one’s sexuality (Bell, 1995; Chapkis, 1997; 
Delacoste \& Alexander, 1987).

Beliefs and the cognitive processes that lead one to consider entering sex work and the influence of prior beliefs has not been explored in the literature. Here, the author shared the participants' reasons for becoming a sex worker. The accounts reflect the diversity of understandings about sex work and the variety of ways these participants made meaning of their entry into sex work.

Interestingly, four of the participants articulated that they had developed their salient understandings of sex work in their early teens or earlier. Kathy developed her understanding from media and stereotyped images of the glamorous side of sex work. Chloe's information came from books and Sally's came from real life family stories:

Chloe: From a young age, I had always had a fascination, from high school age, I was reading books about prostitutes... and nice to have found the good parts about it, the ones from New York who fly around the world.

Sally: I had a dream about it, quite young, it runs in the family... I used to hear the stories from my mum about her great aunty and how her gentleman friend had to wait in the car and how they had to put her in a room, because granny would not allow them to meet the black sheep of the family, but they remember sneaking and seeing her, and she was dripping in gold and furs and diamond rings, and this is going back to the thirties and forties and fifties.

It is not uncommon for people to develop career aspirations in their youths and often claimed "It is something I have always wanted to do" (Moir \& Abraham, 1996). Children frequently aspire to professions, such as an athlete or a model, where their body is the commodity (Bybee \& Wells, 2006). An early desire to be a sex worker has been expressed in some of the sex worker literature; for example, Queen (1994) had ideas about being paid for sex in her preteen years.

Other participants developed their beliefs and became interested in sex work during their adult years. For Alice, who started sex work at the age of 34 , it meant having sex with a variety of people:

Alice: The seed was sown when I was in my mid twenties, in the sixties, and I went to Amsterdam, and looked at those window girls, and I looked at them long and hard, and I thought: "I would like to do what you are doing”, not to sit in the windows, but I knew that they were having sex with people... as somebody who likes to have sex with different people, um, I think that was when I first started thinking. “One day in my life, that's what I'm going to do” (laughter).

Elizabeth had watched people gather for meetings at resorts during her travels, and thought that sex work would be like that, people simply meeting up for a pleasurable experience that was also work. Overall, most of the accounts reflected an understanding that sex work is a positive option.

The exception is Mary, who held a negative view of sex workers; she grew up in a socially isolated and very religious family, which heavily influenced her understandings:

Mary: I would never get involved in anything like that, how dreadful, I used to think, "My god how could those people do that, what kind of women must they be?”.

When people enter an occupation, they bring their understandings with them and during the work related socialisation process reconcile their preconceived ideas with the reality of the job. It can be a difficult process if they have negative understandings of the work and they lack the social support and "subcultural armour" to cope with negative stereotypes (Ashforth \& Kreiner, 1999). This difficulty resonated through Mary's narrative.

For several participants, the attraction of the work was related to their sexuality. Vicky had previous experience as a client and used sex work, particularly in the realm of dominance and submission, to explore her 
own sexuality. Others, like Alice, believed that they could do sex work easily because they enjoyed sex with a variety of people. They wanted to get paid for doing what they enjoyed:

Chloe: I was into screwing anyone and everyone. Um, yes, so I thought right, I can do this job. I didn't have great drug problems and need of money, so that wasn't what made me need to do the job.

Kathy: I needed money and seeing the big flashing lights of the parlour, and I thought well you know, I'm sort of a nymphomaniac at heart anyway so I thought: “Well why not get paid for it?”.

Casey: I was really excited about getting in to it. It wasn't from a feeling about deficit or need or, it was a huge adventure.

In common with these women, many of the participants in a recent New Zealand study indicated that they became interested in sex work because it looked glamorous or exciting or because they wanted to explore their own sexuality (Abel, Fitzgerald, \& Brunton, 2007).

\section{It Is a Very Special Job}

Enjoying one's work contributes to well being and how the work is coped with and carried out. A theme identified in the narratives is that sex work is enjoyable and about more than just the money. This section briefly explores what the participants who view the work positively think and feel about sex work as a job overall. People are often disappointed when a job bears little resemblance to their preconceived notions. When the following extracts are taken into account alongside other portions of these narratives, it seems that notions about how the work might be and how the work is perceived after some time in the industry are similar. The narratives indicate that they are performing out their expectations.

The following extracts provide an indication of factors making the job enjoyable:

Elizabeth: I remember just lying back and having a cigarette and looking at the ceiling and thinking, gosh I'm lucky... just lying back, thinking this is so relaxing.

Kathy: I love slip and slides... I love pampering men and I love them pampering me... I love being a sex worker because you get to be creative on your own.

Zoe: I love it, yeah, it's like sometimes... I'm laughing while I'm fucking. I'll be going, “Oh my god why, this is really cool”.

Alice: Just going to the pure basics of energy and life force, and joining in a physical way with another person. I love dancing for the same reason... I just knew that this was my dream job.

Casey: I loved it... I, um, find it one of the most beautiful things that one can do... it's a real genuine gift and talent I have with it, I’ve got my clients to be relaxed and pampered and loved and cared for.

In describing what they liked about the job, they displayed no uncertainty or ambiguity in their saying they "love it". It has been theorised that looking for the beneficial aspects of the work is an attempt to justify prostitution and make it seem more palatable (Farley, 2004), however, the certainty expressed in these statement indicated that this is not what is happening here.

In addition to benefits to themselves, there is a thread of belief that the work has a positive effect on the client that goes beyond sexual gratification. Some of the participants described their work as therapeutic, healing or educative, as these representative quotes explained.

Zoe: There is no other job where I could do so much good in the world. 
Alice: It's a very special job and it's a very beneficial thing to do for yourself and for your clients if you enjoy sex and you enjoy sharing the love, the energy or whatever it is.

Mary: If they go away happy, they might change their perception... I'm healing them... the whole spiritual side of it, I would like to think, this is what keeps me sane anyway, I could be fooling myself, laughter, I tell myself, well I'm helping them.

In contrast to Mary, for Kathy, there was no uncertainty about the positive effect she has on some clients; she described a client whom she has worked with to improve his confidence, the following extract describes the experience of the phenomenon and provides her with evidence of the usefulness of her work with this client:

Kathy: He walks in now, his head is up and as soon as he sees you there is a big grin, you know it does something for me as well as them and it actually gives me a buzz as well seeing that.

Casey also provided evidence of the impact she had on client's lives.

Casey: It’s extremely gratifying when I come across people and they say, "You had such a powerful effect on me”... It's an honor and a privilege.

Narratives by clients strongly indicated that the encounters had positive effects on their wellbeing (Bell, 1995) and personal relationships (Kinnell, 2006). Disabled clients reported an increase in self-esteem (Sanders, 2007). Drawing on the notion of sex work as beneficial helps explain and justify the work. Mary made explicit a common cognitive process. People implicitly attempt to understand the meaning of their work and how one understands one's meaningfulness in the world, especially at work, which has a direct impact on one's feelings of value as a human being (Wrzesniewski, Dutton, \& Debebe, 2003).

\section{Acting up or Acting out?}

An identified theme in the narratives is one of being in a sex worker role while at work. For most of these women, having a work name and going into and out of role was a useful strategy that enabled them to do their work in a way that was comfortable for them. For some, it allows an expression of self that is not permissible in their other worlds. The meaning of taking on another name and a work role is far more complex than simply maintaining some separation between work and non-work worlds. The observable behaviours of these women in relation to persona and role-play may appear similar to the casual observer; however, the reasons and meaning for these behaviours vary widely between individuals and contexts. This section explores the participants' understandings of what work name, role and persona means to them.

When people enter the sex industry, they are usually given or asked to choose a work name and advised to develop a work persona. Considered to be a universal phenomenon of sex work (Sanders, 2005), choosing a work name and acting out another personality while at work to achieve clear role separation and protect identity is an important aspect of maintaining the psychological health of sex workers (McVerry \& Lindop, 2005). These extracts illustrated the workers' understandings of the use of a work name.

Nina: I mean by having another name, it's like you're leading two lives so you can go from normal life, walk into your job, you're a completely different person, like two different worlds and if you keep them separate, it's easier to deal with.

For Nina, the separation allowed her to easily define and separate her role as mother and active member of the community from her job as a sex worker.

For Chloe, the name was about keeping home away from work: 
Chloe: I go Ok, when you are here between 10 and 12 or whatever, you become so and so. So you leave yourself at home and thinking about yourself, the kids and the husband and at this place you become someone else, you put on a different hat, you are wearing lovely dresses and all this sort of thing. So I did that for a while and then as I got older I didn’t need to worry about that anymore.

This representative explanation is not unusual. Abel et al. (2007) found that one of the benefits of sex work was that it provided a welcome break from home and family. The following extract illustrates this well:

Sally: on a good night you look forward to the girls and you have fun and you get paid for it, you dress up and you wear makeup and clothes... personally, how I look at it is a break from my child, it's being around the girls, cracking fun at the boys and getting paid for it. How good.

For some participants, the name was directly connected to work roles:

Sally: Like I have different names in different places.

Kathy: As soon as I walk through those doors, I change from Kathy to Melissa, I'm in character, the glasses come off, um the sexy clothing comes on and I'm in character... I like being in character.

Elizabeth: Instead of using the shortened version of my name, I actually extended into the full version and made it more formal... which sounded more grown up.

Sally changed her name to fit in with how she was presenting herself as a sex worker, she explained that the work requirements, and thus, her presentation is quite different in a large city than in a small rural town. Kathy used the name rather like another piece of her character costume; it reflected her personal style and attitude to work.

Interestingly, they did not mention issues of safety or anonymity as a reason for having a work name, although most of the participants described being given an explanation similar to the one Elizabeth was given when she first started sex work:

Elizabeth: They later explained as you walk down the street and someone calls out to you and you can pretend that's not you and I thought well that's nutty.

However, as shown in these extracts, in practice, this is not what it actually means for these women.

Not all workers chose a work name or persona. Some participants chose to use their real name because they do not wish to separate work self from non-work. Casey had little separation between work and non-work life and used her real name. Both Alice and Casey were "out” to most people in their social worlds.

Alice: I never changed my name I never saw a need for that, it was just me.

Elizabeth: Actually, I thought it never made sense to me to have another persona, why would I want to disengage or not be me?

Elizabeth, Alice and Casey, were most consistent between work and non-work roles:

Alice: I always said if I had to act I would stop, that wouldn’t be right at all, and I didn’t, you know I couldn’t live a lie.

Elizabeth: I was quite comfortable being a sex worker, very comfortable, very proud actually, and I never um, I didn't make up another persona, probably just a less garrulous (laughter) one.

These extracts reflect an idea that acting may mean dishonesty or discomfort with being a sex worker, 
however, some other participants who described their role experiences in detail did not impose this meaning on role playing or persona.

Two of the threads to the participants explanations rationalized and normalized taking on roles. The first was that having roles for different situations is a usual part of being in the world. The second reflected the experience of being a woman. Being in role, having a persona or acting up to the clients does not mean that the "real person" is somehow left out of sex work. In these threads, there is an implication of integration of self into the role rather than the separation discussed earlier. Mary’s explanation summed it up:

Mary: I am who I am with my kids and I'm who I am with my friends and I'm who I am with family and I am who I am with my clients, but I'm still me. I might be different in different ways with all of them but I'm still me...

This extract reflects the explanations given in other narratives, for these women, the sex workers' role they took on at work was functional and worked in the same ways as other roles; they were acting in a way that was appropriate to the situation. They saw the sexualized interaction as an exaggeration or variation on usual heterosexual social interactions.

Elizabeth: But you see that in the straight world too, where women work hard to, you know, you can see scenarios where women are working hard to be bright and light and be sexually available.

Acting up to dominant understandings of how women are required to be, an exaggerated expression of femininity; it is more of the same rather than different. Alice took great pleasure in being a lover to her clients. Kathy, Sally and Zoe took on such role playing with relish. Pleasure and delight in having a safe place to play with sexuality was evident in the telling. There was much laughter and movement as they explained the benefits of being in role:

Kathy: I like being in character for that amount of hours and you know playing that, ... maybe it's just the alter ego coming out and I think that it's great being, you know, reinvent yourself... I can strip off naked and prance around the room and feel so confident in the room. I could probably do more things in the room with a stranger than I can with my boyfriend... it’s done oodles for my confidence.

Both Sally and Kathy explained that they were shy around someone they were attracted to, but were outgoing and full of confidence around clients, because there is no desire to form any emotional attachment. For these women, it is apparent that a part of themselves that is coming out to play is constrained from expression in usual day-to-day life. The combination of having control of the situation and lack of emotional attachment to the client allows for confident expressions of sexuality that are not possible in the private sphere, a notion that was supported by Kontula (2007) who suggested that "It seems that at least in some cases, the internal power relation of sex work can emancipate prostitutes towards more pleasurable and self-confident sexuality” (p. 13). It is not always emotionally safe to act out fantasies with primary lovers and it is certainly not safe for a woman to "prance" in many social situations, nor is it socially acceptable to have large numbers of lovers. This idea is given strength by the use of words like "whore”, "ho", and other terms that are related to sex work to describe women who do act out and act up sexually so as to simultaneously conform to and contradict currently acceptable ways of being a woman.

The women were in control of how they presented themselves; this may change from day-to-day or client-to-client. Zoe changed according to how she perceived the client:

Zoe: As soon as you get on their wavelength and you're just changing from different wavelength to different 
wavelength and being able to just do that ten times in a night.

For Zoe, being in role was related to what was happening in the work context. In contrast, Mary performed in accordance with how she felt about herself as a sex worker and her clients. In some days, she relished taking on and using her position to express what she sometimes thought about clients in general:

Mary: Sometimes, I want to be able to dress up and be this nasty bitch to them, it’s my way of thinking, well fuck you, I'm thinking, fuck you for being a cheater on your wife, fuck you for being, full stop.

It enabled her to express her distaste for clients in a way that is safe for her and them. It discharged the tension and internal conflict she experienced in relation to being a sex worker. In other days, it is different, she is her usual kindly self at work. In contrast to the explanations given at the beginning of this section, Mary used the situation to deliberately reduce separation, while still seeing herself as in a role.

\section{Conclusions}

The participants did not enter the industry on impulse or only from dire financial need. Some became attracted to sex work in their adult years whilst others became interested in sex work prior to their teen years in much the same way as another individual who may develop an interest in any other occupation. Most chose sex work because it fitted with their traits and skills. In this study, sex workers clearly understood their work to have meaning beyond that of being a sexual object while at work. Most participants experienced a sense of satisfaction and enjoyment from the work; the reasons for this include having a sense that commercial sex fulfills a wider social need for clients, the culture of the workplace and enjoyment of the sexual aspects of the job.

One of the core principles of the sex industry is that the sexual connection takes place within boundaries that are usually set by the sex worker to fit in with her style of working. Having a work persona both creates boundaries and allows for expression of self. The narratives indicated that the sex workers' role is considered to be an exaggeration or variation of usual heterosexual interactions. For most participants, the role provided a safe place to express their own sexuality in ways they do not in their usual social world.

There are implication in these results for further research and for those who work with sex workers, such as social workers, counselors and health providers. For those in the caring professions who work with sex workers the positive aspects of working in a job, that is chosen because it fits in with personal beliefs and attributes, need to be acknowledged. Those in the caring professions may need to challenge their own beliefs about sex work and not assume that sex workers lack agency or will wish to be assisted to leave the industry.

Future research may need to further explore sex workers' thoughts and beliefs about their work rather than continue to focus on physical health related issues. Investigations related to paths into sex work need to take into account a wide variety of issues other than victimization, income and physical working conditions. Researchers and theorists could well do with spending effort on questioning why the validity accounts, such as these are denied by many feminists, some theorists and those in the helping professions. They could also ask "Who benefits from invisibilising the positive?".

The author suggests following the advice of Dworkin (1993) who stated that, "What matters here is to try to learn what the prostituted woman knows, because it is of immense value”. By listening to what the women concerned have to say about their lives, an alternative understanding of the sex work experience can emerge. These findings challenge the notions that: (1) Most sex workers are only in the industry for 
the money; (2) Sex work is not related to sexuality; and (3) Sex work is chosen differently to other work or career options.

\section{References}

Abel, G., Fitzgerald, L., \& Brunton, C. (2007). The impact of the Prostitution Reform Act on the health and safety practices of sex workers. Retrieved 2008, from http://www.justice.govt.nz/prostitution-law-review-committee/publications/impact-health-safety/index.html

Ashforth, B. E., \& Kreiner, G. E. (1999). “How can you do it?”: Dirty work and the challenge of constructing a positive identity. Academy of Management Review, 24(3), 413-434.

Bell, S. (Ed.). (1995). Whore carnival. New York: Automedia.

Bernstein, E. (2007). Sex work for the middle classes. Sexualities, 10(4), 473-488.

Brewis, J., \& Linstead, S. (2000). Sex, work and sex work. London: Routledge.

Bybee, J. A., \& Wells, Y. V. (2006). Body themes in descriptions of possible selves: Diverse perspectives across the life span. Journal of Adult Development, 13(2).

Chapkis, W. (1997). Live sex acts: Women performing erotic labour. New York: Routledge.

Delacoste, F., \& Alexander, P. (Eds.). (1987). Sex work: Writings by women in the sex industry. Pittsburg: Cleis Press.

Dworkin, A. (1993). Prostitution and male supremacy. Retrieved May 30, 2008, from http://www.nostatusquo.com/ACLU/ dworkin/MichLawJourI.html

Farley, M. (2004). "Bad for the Body, Bad for the Heart”: Prostitution harms women even if legalized of decriminalized. Violence Against Women, 10(10), 1087-1125.

Harding, S. (1991). Whose science? Whose knowledge? Thinking from women's lives. New York: Cornell University.

Hein, S. F., \& Austin, W. J. (2001). Empirical and hermeneutic approaches to phenomenological research in psychology: A comparison. Psychological Methods, 6(1), 3-17.

Jackson, L. A., Bennett, C. G., \& Sowinski, B. A. (2007). Stress in the sex trade and beyond: Women working in the sex trade talk about the emotional stressors in their working and home lives. Critical Public Health, 17(3), 257-272.

Jordan, J. (2005). The sex industry in New Zealand: A literature review. Wellington: Ministry of Justice.

Kinnell, H. (2006). Clients of female sex workers: men or monsters? In R. Campbell, \& M. O’Neill (Eds.), Sex work now. Cullompton, Devon: Willan.

Kontula. (2007). Sex worker and her pleasure. Retrieved March 14, 2008, from http://myweb.dal.ca/ mgoodyea/Documents/Sexuality/Sex\%20workers\%20view\%20to\%20sexual\%20pleasure\%20Kontula\%202007.doc

Leigh, C. (1997). Inventing sex work. In J. Nagel (Ed.), Whores and other feminists. New York: Routledge.

McVerry, S., \& Lindop, E. (2005). Negotiating risk; how women working in massage parlours preserve their sexual and psychological health. Health Care for Women International, 26, 108-117.

Mistress, J. (2002). Private theatre: Personal observations and reflections of a dominatrix. Kew, Victoria: Domina.

Moir, J., \& Abraham, C. (1996). Why I want to be a psychiatric nurse: Constructing an identity through contrasts with general nursing. Journal of Advanced Nursing, 23, 295-298.

Perkins, R., \& Lovejoy, F. (2007). Call girls. Crawley: University of Western Australia Press.

Phoenix, J. (2000). Prostitute identities: Men, money and violence. In R. Matthews, \& M. O’Neill (Eds.), Prostitution (pp. 225-243). Hants, England: Dartmouth Publishing Company.

PLRC (Prostitution Law Review Committee). (2008). Report of the Prostitution Law Review Committee on the operation of the Prostitution Reform Act 2003. Retrieved 2008, from http://www.justice.govt.nz/ prostitution-law-review-committee/ publications/plrc-report/index.html

Plumridge, L. (2005). Good, bad and indifferent: Emotional labour and prostitution. In A. Kirkman, \& P. Moloney (Eds.), Sexuality down under: Social and historical perspectives (pp. 151-164). Dunedin, N. Z.: University of Otago Press.

Queen, C. (1994). The call girl. In K. R. Stubbs (Ed.), Women of the light: the new sacred prostitute: Larkspur.

Sanders, T. (2005). It's just acting: Sex workers strategies for capitalizing on sexuality. Gender, Work \& Organization, 12(4), 319-342.

Sanders, T. (2007). The politics of sexual citizenship: Commercial sex and disability. Disability and Society, 00022(00005), 439-456.

Smith, J., Jarman, M., \& Osborn, M. (1999). Doing interpretive phenomenological analysis. In M. Murray, \& K. Chamberlain (Eds.), Qualitative health psychology (pp. 218-240). London: Sage.

Stubbs, K. R. (Ed.). (1994). Women of the light: The new sacred prostitute. Larkspur, Cal.: Secret garden.

Wrzesniewski, A., Dutton, J. E., \& Debebe, G. (2003). Interpersonal sensemaking and the meaning of work. Research in Organizational Behavior, 25, 93-135. 